\title{
Simulation and fabrication of active laser mirrors
}

\author{
M. Knopf \\ Aalen University, D-73430 Aalen, Germany \\ M. Hänle \\ Aalen University, D-73430 Aalen, Germany \\ R. Boerret \\ Aalen University, D-73430 Aalen, Germany \\ rainer.boerret@htw-aalen.de \\ A. Kelm \\ Aalen University, D-73430 Aalen, Germany
}

Common laser mirrors made of copper for high power applications in metal working have to be cooled in order to minimize thermal deformations. This paper presents a new approach. The principal idea is to use metal-coated mirrors made of silicon carbide (Sic) and to preheat them. The mirror surface shall be manufactured so that the induced heat deforms it to the ideal form. Simulations concerning the thermal behavior prove the feasibility of the idea. The simulations are verified by interferometric measurement during heating. [DOI: 10.2971/jeos.2010.10005]

Keywords: silicon carbide, laser mirrors, thermal behavior, deformations

\section{INTRODUCTION}

Mirrors made out of ceramics like SiC have shown their performance in several space optic applications. Main drivers for the usage of that kind of materials were low thermal expansion and the possibility of lightweight structures to reduce the mass of the mirror [1].

The goal of this project is to explore the possibility if these advantages can be used in the field of high power laser beam shaping. State of the art mirrors in laser cutting and welding are diamond turned out of copper, showing a surface error of around $1 \mu \mathrm{m} \mathrm{PV}$ and a surface roughness of around $2 \mathrm{~nm} \mathrm{R}_{\mathrm{a}}$. Those mirrors require a sophisticated cooling system to avoid thermal deformation and mechanical changes of the copper mirrors [2]. Typically the temperature deviation during operation has to be stabilized within a band of $1 \mathrm{~K}$ in order to achieve a deformation of less than $633 \mathrm{~nm}$. Ceramics have a much lower thermal expansion coefficient, thus allowing a wider specification of the allowable temperature change in order to attain the same deformation as copper mirrors and can be operated at higher temperatures [2]. This may give the possibility to minimize thermal deformation by not cooling the mirror but to heat it to a higher operating temperature where it has its optimum optical performance. The heating from the laser beam is supported by electrical heating to keep the operating temperature constant in a broader bandwidth. This results in a less sophisticated system configuration. Typical means of correcting thermally induced deformations in large mirrors are electromechanical actuators [4] or by thermally addressed tubes [5], which is inapplicable for smaller mirrors needed in beam shaping and guiding. Since such a $\mathrm{SiC}$ mirror must also be cost competitive with a copper

mirror, the mirror surface must be made in the substrate. An additional CVD layer that is common with SiC mirrors for astronomical purposes is too expensive for this application. So the simulation and the manufacturing address only surfaces in the substrate.

This project covers two topics. The first one is the development of a process chain for the manufacturing of $\mathrm{SiC}$ mirrors for high power lasers. Since the mirror is to be fabricated in series production the process must be within the economic boundaries. In this first investigation an interferometrically measurable surface is sufficient to test the heat influence. The manufacturing time limit is 2 hours. As test part a concave sphere with radius $150 \mathrm{~mm}$ was used. The manufacturing processes used were subaperture processes which can be used to produce also free form surfaces.

The second part is the survey of a SiC mirror under thermal load. Several simulations of the thermal behaviour of such a pre-heated and a non-heated mirror were performed and are presented here. Finally a comparison between simulation results and measurements of first test parts are presented.

\section{SIMULATION OF THE THERMAL BEHAVIOUR AND DEFORMATIONS}

In a first step, CAD-Models of actual test parts with a concave spherical (diameter $52 \mathrm{~mm}$, radius of curvature $150 \mathrm{~mm}$ ) surface were created and exported into a FEM-simulation software. In preparation of further tests, different simulations 
Maximum temperature over time

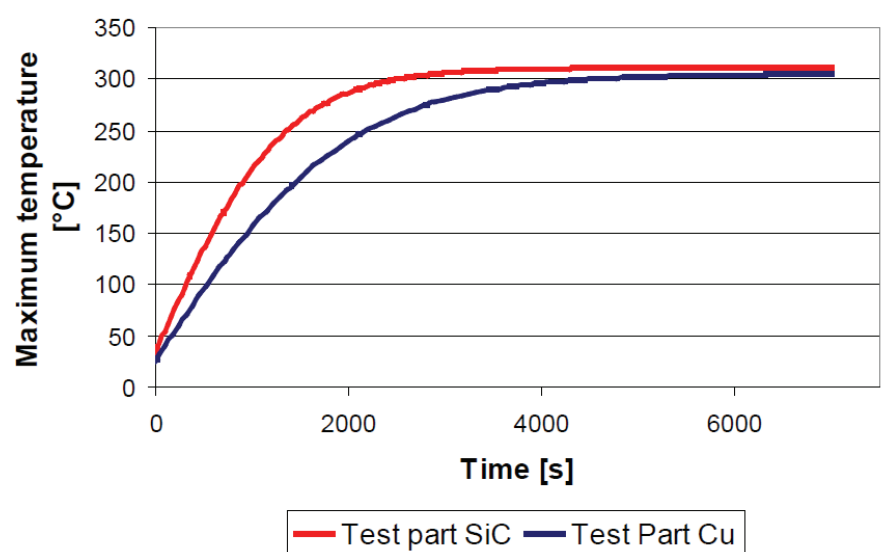

FIG. 1 Comparison of the simulated maximum temperature over time for a test part made of SiC and copper.

Deformation over time, comparison

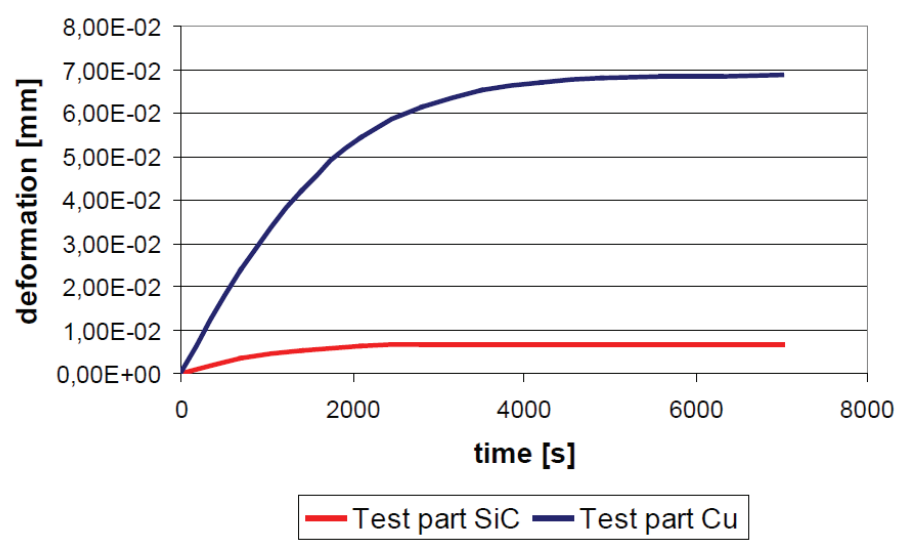

FIG. 2 Simulated deformation of the test parts made of SiC and copper.

have been realized. In a first step the difference between copper mirrors and $\mathrm{CeSiC} \circledast$ mirrors without any mountings. The induced heat flow of $24 \mathrm{~W}$ corresponds to the induced heat during operation of an $8 \mathrm{~kW} \mathrm{CO}$ laser mirror with a reflectivity of $99.7 \%$.

For simplicity only heat transfer by radiation was taken into account. Figure 1 shows the heating up of the probe part with the maximum temperature as figure of merit. Clearly visible, the simulated $\mathrm{SiC}$ part heats up faster than a similar copper part. The reason for this is the lower thermal capacity of copper. There virtually is no difference in the maximum temperature of the two materials. Whilst the maximum temperatures didn't show significant differences, the deformation did. In Figure 2 the difference between the extreme values over the mirror surface is shown as a value for the deformation from the ideal form.

Figure 2 shows the main advantage of SiC. Apart from a much lower density than copper, $\mathrm{SiC}$ has a significant smaller thermal expansion coefficient. That being the reason for the significant smaller deformation of the $\mathrm{SiC}$ test part. In order to verify the simulations and their accuracy another simulation model consisting of the test part and its mounting was devel- oped. In this model the induced heat flow was of $30 \mathrm{~W}$, paying respect to the thermal foil used during the sample tests.

Only simulations of $\mathrm{SiC}$ test parts were realized. Simulations have shown that the maximum temperature tended to a value of about $130^{\circ} \mathrm{C}$ in a state of equilibrium after more than 3 hours of heating.

Therefore two simulations where made. First a test part at room temperature $\left(21^{\circ} \mathrm{C}\right)$ was heated up over 1 hour and its deformation along the z-axis was evaluated. Afterwards a simulation in which the part was preheated up to $115^{\circ} \mathrm{C}$ in order to prevent an overshoot of the temperature, which would take too long to cool down, was realized.

As shown in Figure 3 the temperature change of the nonheated part was of $\sim 80 \mathrm{~K}$ in the case of the non-heated part, whereas the difference was of only $\sim 20 \mathrm{~K}$ in the case of the preheated part.

As a result of the significantly smaller temperature change the deformation of the part is also significantly smaller as shown in Figure 4. Instead of a PV-value of around $5.5 \mu \mathrm{m}$, the deformation of a preheated part is significantly smaller of around $1.4 \mu \mathrm{m}$.

After these simulations one was able to state that the preheating of a test part greatly reduces the deformations induced by further heating.
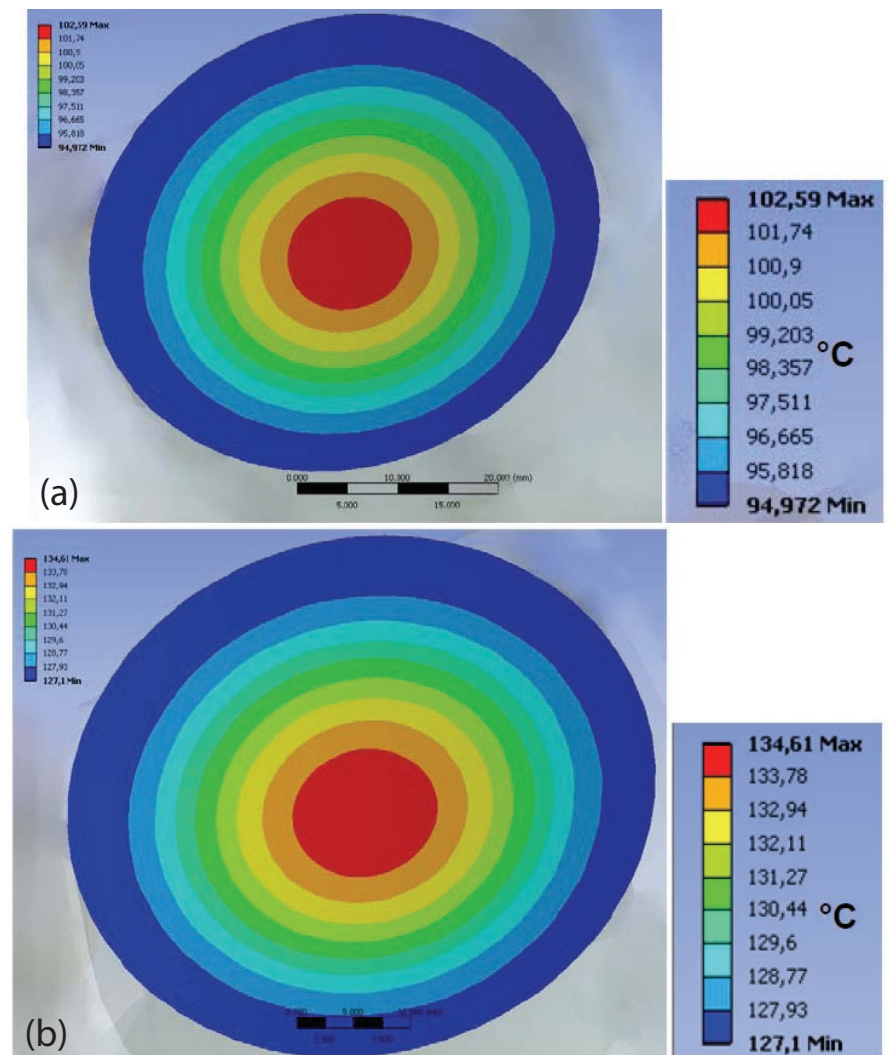

FIG. 3 Comparison of the simulated temperature profiles over (a) a non-heated part and (b) a preheated part after 1 hour, heat flow of $30 \mathrm{~W}$. 

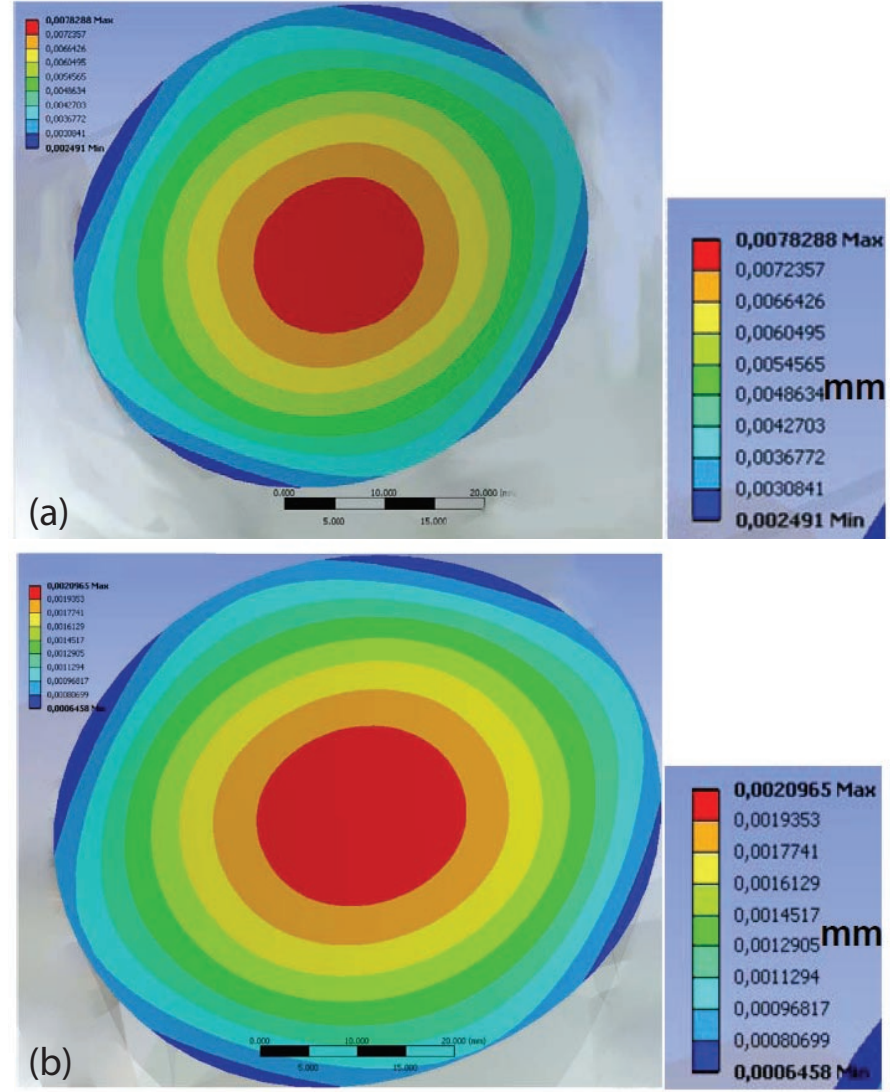

FIG. 4 Simulated thermal induced deformations of an (a) non-heated $\left(\mathrm{T}=21^{\circ} \mathrm{C}\right)$, (b) preheated $\left(T=115^{\circ} \mathrm{C}\right)$ test part after one hour of heating, heat flow of $30 \mathrm{~W}$.

\section{FABRICATION}

The fabrication of the test part should use a fast process chain in order to meet economic boundaries. The goal was to manufacture the mirror in less than two hours and achieve a surface that can be measured interferometrically. All processes used are subaperture and suitable for free form surface production.

The probe parts were grinded in an optical grinding machine, leading to a rough surface with clearly visible structures (see Figure 5). In order to reduce those structures, a further fine grinding step was applied which also corrected the somewhat clearly deviated surface with around $5 \mu \mathrm{m}$ PV. The tool used was based on Trizact diamond foil by $3 \mathrm{M}$. One was able to reduce the surface error over a diameter of $48 \mathrm{~mm}$ by to around $1.6 \mu \mathrm{m}$ in about than $1 \mathrm{~h}$ (see Figure 6). Figure 7 shows the tool on one of the probe parts. One can clearly see the small footprint of the tool on the SiC-surface. The parts are not interferometrically measurable after the fine grinding step, so a smoothing step has to be done afterwards. The smoothing step consisted of a treatment with diamond slurry at a diamond grain size of $6 \mu \mathrm{m}$ combined with a polyurethane foam pad.

After less than 30 minutes, the surface roughness was of a value of around $12 \mathrm{~nm} \mathrm{R}_{\mathrm{a}}$ over the whole surface (see Figure 8). This was sufficient for interferometrical testing and is also sufficient for high power laser application. One can clearly state that the grinding marks were removed and the material structure consisting of 3 phases of the $\mathrm{SiC}$ is the predominant factor for the surface roughness. The asymmetric er-

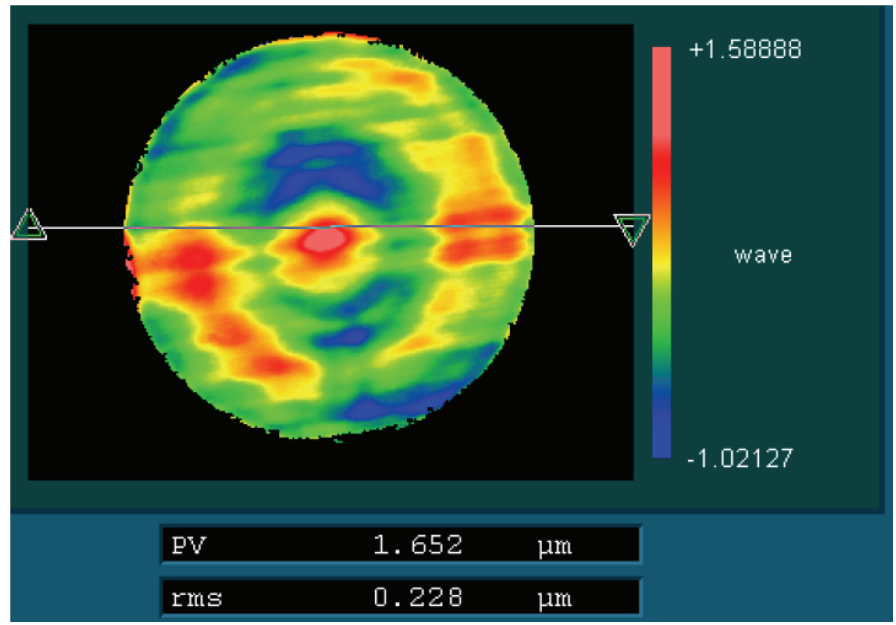

FIC. 5 SiC mirror surface after polishing step (left) and after grinding step.

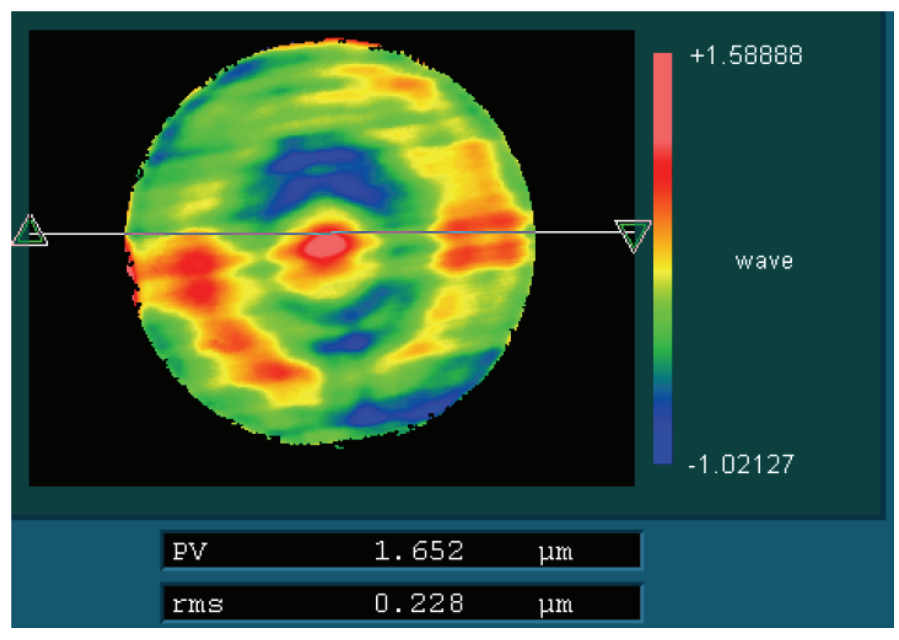

FIG. 6 Interferometrical measurement of the polished mirror surface.

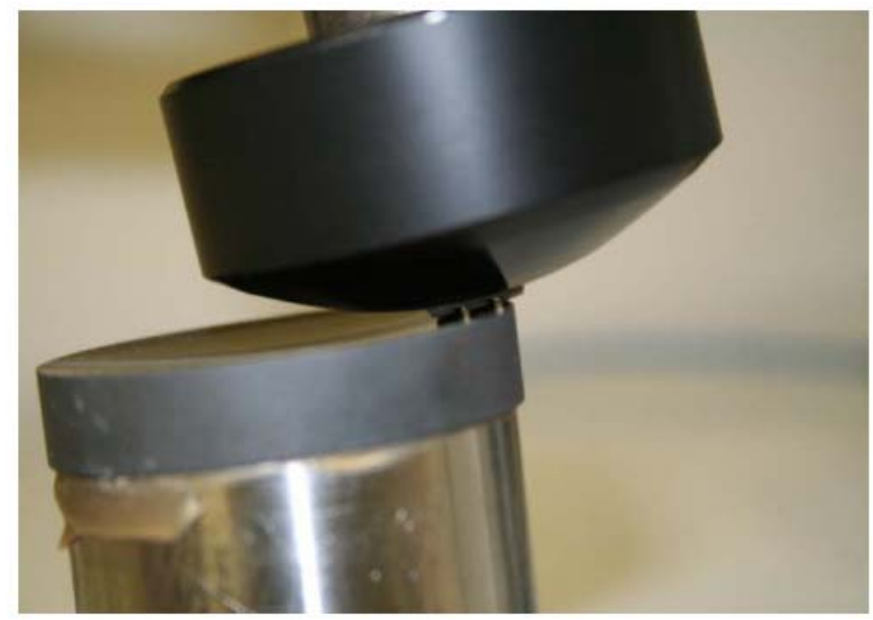

FIG. 7 Newly developed fine grinding tool on the mirror surface.

rors derive from a still too large footprint of the tool. In further steps different tool sizes will be investigated and surface deviation will be decreased.

With the manufacturing of an interferometrically measurable surface in less than two hours the economic objectives were met and the process chain can also be used to produce free 


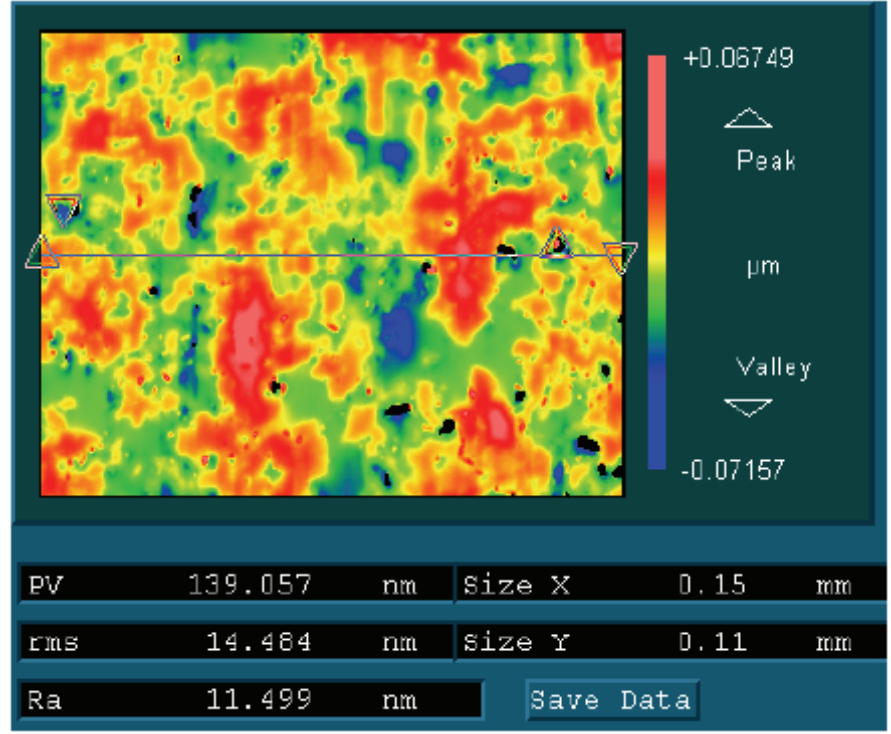

FIC. 8 Microinterferometrical measurement of the mirror surface, phase shift mode, $40 \times$ zoom

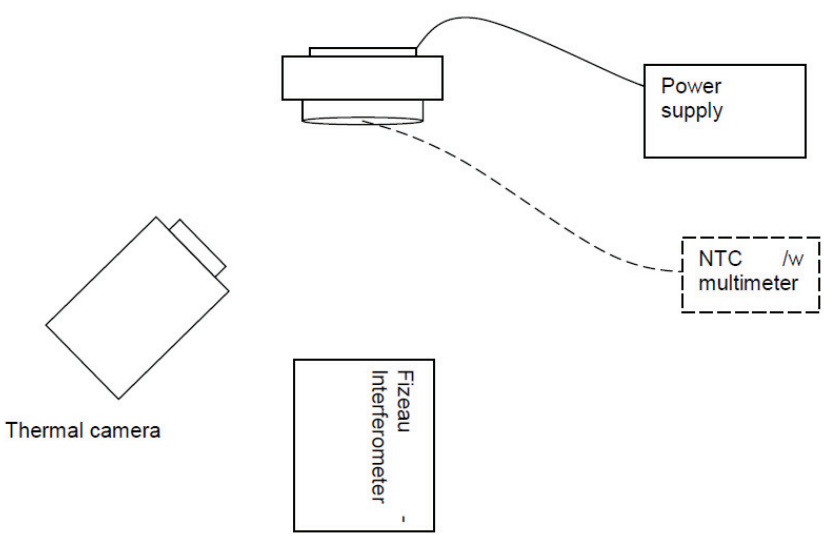

FIG. 9 Scheme of the measurement set-up.

form surfaces. That however must be investigated in further works.

\section{VERIFICATION OF THE SIMULATIONS}

In order to verify the accuracy of the realized simulations, a simple yet effective measurement setup was realized.

Via a thermo foil glued onto the back of a test part made of $\mathrm{SiC}$, a heat flow of $24 \mathrm{~W}$ was induced. The whole heating was set up in a Fizeau-type interferometer so that the surface shape could be measured during the process of heating up. By comparing the actual interferogram to the interferogram of the unheated test part the deformation can be calculated.

Two ways of controlling the maximum temperature of the surface were chosen.

In a first step, the temperature was measured by a NTCthermistor attached to the center of the mirror surface. This set-up soon was replaced by a measurement with a thermal camera (see Figure 9). As shown in Figure 10, the measured
Maximum temperature over time, comparison

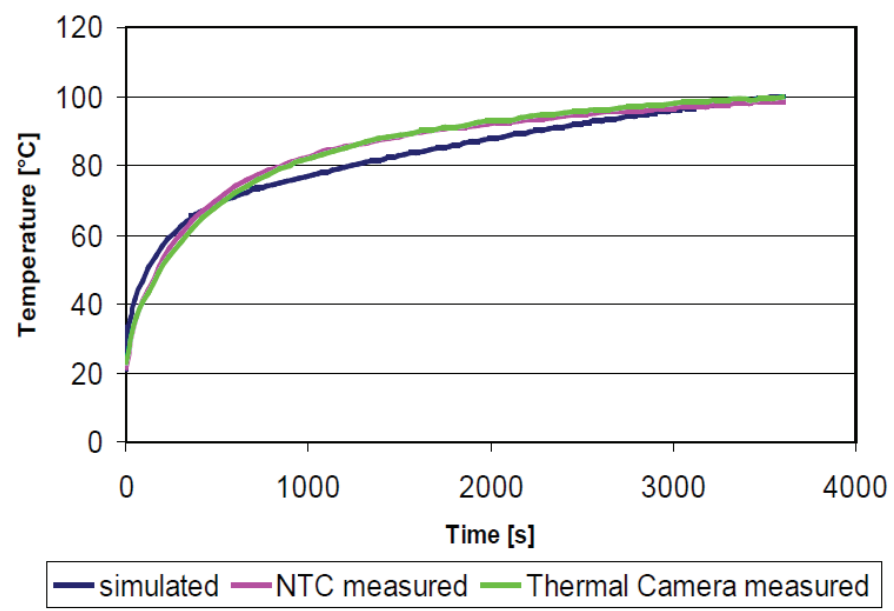

FIG. 10 Comparison of the simulated and measured maximum temperature.

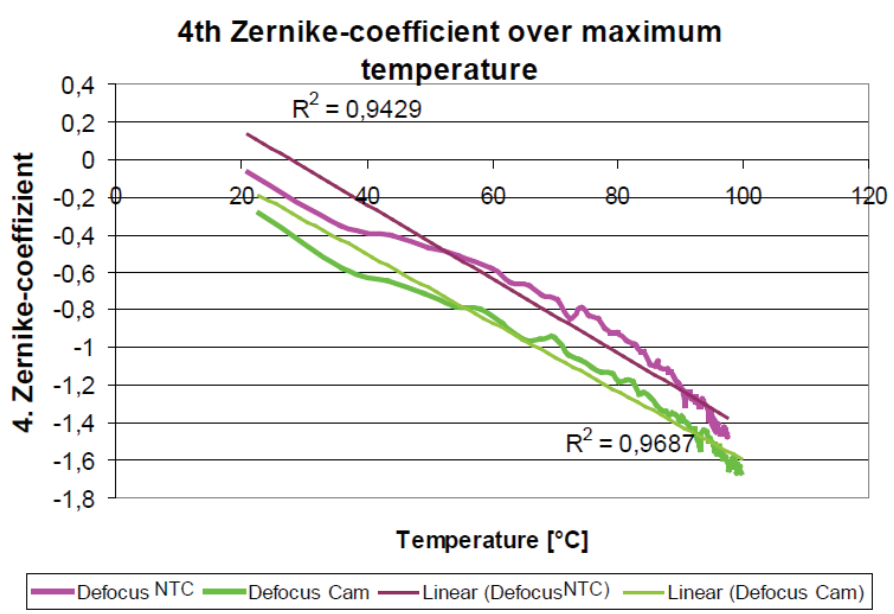

FIC. 11 Behavior of the measured $4^{\text {th }}$ Zernike-coefficient in respect to maximum temperature during heating.

temperature development over time showed a good resemblance to the simulated graph. The deviations between simulation and reality derive from the simulation coefficients, which were estimated constant over the whole temperature range. Nevertheless the maximum deviation is around $10 \%$ both measured with the NTC and the thermal camera.

As the simulation primarily showed a spherical deformation due to the induced heat, the $4^{\text {th }}$ Zernike coefficient representing the spherical deformation was recorded and correlated to the temperature, showing a nearly linear behavior, shown in Figure 11. In addition, one was able to compare the temperature distribution over the mirror surface to the simulated distribution.

Due to the fact that the thermal camera was set up in a tilted way, the thermal profile over the surface is tilted. Nevertheless one could see a temperature gradient of $6 \mathrm{~K}$ over a distance of approximately $48 \mathrm{~mm}$ (see Figure 12), which correlates well with the simulations (see Figure 3(a)) of a non-preheated part after 1 hour of heating. The surface deformation after $60 \mathrm{~min}-$ utes of heating showed a nearly spherical shape, yet the principal shape of the deformation, with a higher deformation in the middle, is visible. Only the measured value of the defor- 

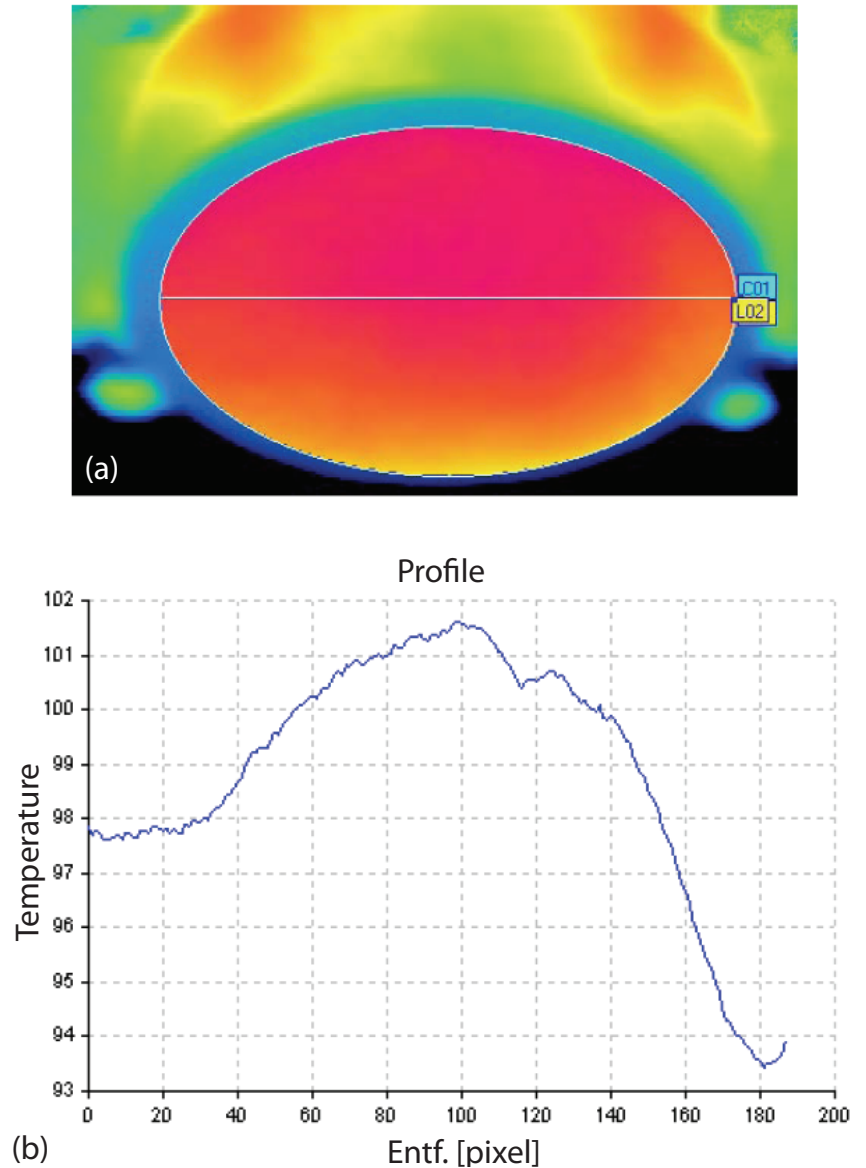

FIG. 12 (a) False-colour image of the heated mirror surface with adapted emission coefficient, (b) temperature profile over the line in (a), tilt due to set-up of the camera.

mation (see Figure 13 where PV is approximately $2 \mu \mathrm{m}$ over $48 \mathrm{~mm}$ diameter) is smaller than the simulated one (see Figure 4 (a) where PV is $4 \mu \mathrm{m}$ over $52 \mathrm{~mm}$ diameter).

\section{CONCLUSION}

One was able to show that the principle idea of preheating laser mirrors greatly reduces the expected deformations, as the simulated values correspond well to the measured ones. All the processes and simulations were done on a spherical test part with subaperture tools, thus a transition to another form, e.g. an off-axis paraboloid should be feasible.

Yet the deformations are still too big. In a next step, the expected deformations have to be considered during the manufacturing process in order to have an ideal surface form at the operating temperature. Also the manufacturing must be refined to improve PV values from the achieved $2 \mu \mathrm{m}$ to $1 \mu \mathrm{m}$ and surface roughness from $12 \mathrm{~nm}$ to $5 \mathrm{~nm} \mathrm{rms}$ in or-

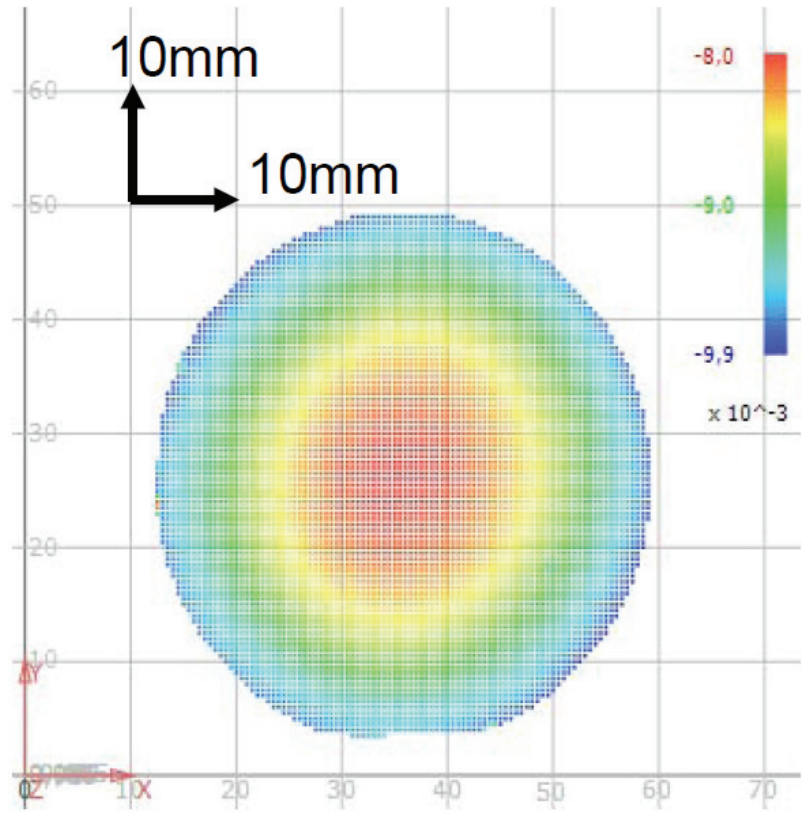

FIG. 13 Measured deformation after 1 hour of heating, PV is approximately $2 \mu \mathrm{m}$.

der to be competitive with the state-of-the-art copper mirrors. One could also think of a refinement of the simulations with respect to the parameters. Nonetheless the first results are promising and the idea of a laser mirror which deforms itself into the ideal shape by being heated is feasible.

\section{ACKNOWLEDGEMENT}

The work is supported by the Landesstiftung BadenWürttemberg foundation under the contract " $\mathrm{F}^{3}$ - Laseroptik" and by the BMBF/AIF under the contract "Keraform".

\section{References}

[1] H. Harnisch, B. Kunkel, M. Deyerler, S. Bauereisen, S. Bauereisen, and U. Papenburg, "Ultra-lightweight C/SiC mirrors and structures" EAS Bulletin 95, 148-152 (1998).

[2] G. Buchfink, and N Leibinger-Kammüller, Werkzeug Laser - Ein Lichtstrahl erobert die industrielle Fertigung (Vogel Verlag Und Druck, Germany, 2006).

[3] www.spring8.or.jp/pdf/en/ann_rep/96/P215-217.pdf

[4] C. Del Vecchio, R. Biasi, A. Riccardi, and D. Gallieni, "Designing the actuator for the next-generation astronomical deformable mirrors: a multidiscplinary and multiphysics approach" (COMSOL Conference, Hanover, 2008).

[5] G. Vdovin, and M. Loktev, "Deformable mirror with thermal actuators" Opt. Lett. 27, 677-679 (2002). 